\title{
Avaliação de egresso da área da saúde: uma revisão
}

\author{
Assessment of graduates in the health area: a review
}

\author{
Tamiris Mariani Pereira Desiderio' (D) tamiris.desiderio@unesp.br \\ Ana Silvia Sartori Barraviera Seabra Ferreira' (D) ana.ferreira@unesp.br
}

\section{RESUMO}

Introdução: Este trabalho apresenta uma revisão da literatura sobre as experiências de avaliação de egressos de cursos de graduação da área da saúde no Brasil, com o desenvolvimento de processos a partir do protagonismo do egresso e de sua importante atuação na verificação da qualidade do ensino superior.

Objetivo: Este estudo teve como objetivo conhecer experiências de avaliação de egressos de cursos de graduação da área saúde no Brasil, de modo a identificar processos e o protagonismo do egresso na verificação da qualidade do ensino superior com foco nos cursos de Medicina e Enfermagem.

Método: Foi realizada uma metassíntese, uma modalidade da revisão de literatura, com a finalidade de analisar qualitativamente estudos que tratam da temática da avaliação de egressos do ensino superior. A busca de produções científicas sobre o tema teve como ponto de partida a seguinte questão "Como são avaliados os egressos de ensino superior da área médica no Brasil?". Optou-se por realizar uma busca nas principais bases de dados da área da saúde: PubMed, Web of Science, LILACS, IBECS e SciELO. Obteve-se um total de 245 trabalhos. Adotaram-se os seguintes critérios de inclusão: 1. trabalho com desenvolvimento de questionário de avaliação de egressos; 2 . trabalho com avaliação de egressos; 3 . trabalho com participação de egressos; 4 . trabalho com indicadores de qualidade na educação superior; 5 . desenvolvimento de metodologias de avaliação da educação superior. Selecionaram-se 13 artigos. Cabe ressaltar que para ser incluído no estudo o trabalho deveria se enquadrar em no mínimo três critérios.

Resultado: As evidências permitem concluir que o egresso participa do processo de avaliação de forma singular, pois o protagonismo dele fica nítido nos estudos analisados, seja como entrevistado ou sujeito que responde ao questionário desenvolvido com métricas científicas.

Conclusão: A avaliação de egressos é uma importante ferramenta estratégica utilizada pela gestão de instituições de ensino, podendo ser considerada uma política pública de significativo impacto. As evidências ratificam a necessidade de incorporação de egressos também como protagonista nos processos de autoavaliação institucional.

Palavras-chave: Educação em Saúde; Educação Superior; Estudo de Avaliação; Egresso.

\section{ABSTRACT}

Introduction: This work presents a literature review on the experiences of evaluating graduates from undergraduate health sciences courses in Brazil with the development of processes centered on the graduate and his/her important role in verifying the quality of higher education.

Objective: To understand the experiences of evaluating graduates from undergraduate health sciences courses in Brazil, identifying processes and the protagonism of the graduate in verifying the quality of higher education with a focus on medical and nursing courses.

Methodology: A meta-synthesis, a type of literature review, was conducted with the purpose of qualitatively analyzing studies that address the theme of the evaluation of higher education graduates. The search for scientific productions on the subject had as its starting point the following question "How are higher education graduates in the medical field evaluated in Brazil?" We opted to perform a search in the main health databases PubMed, Web of Science, Lilacs, IBECS and SciELO. A total of 245 studies were found. The following inclusion criteria were then applied: 1-Work involving the development of a questionnaire for evaluating graduates; 2-Work involving the evaluation of graduates; 3-Work involving the participation of graduates; 4- Work involving quality indicators in higher education; 5- Development of methodologies for the evaluation of higher education. Following the application of these criteria, 13 articles were selected. It should be noted that in order to be included in the study, the work had to meet at least three criteria.

Results: The evidence allows us to conclude that the graduate participates in the evaluation process in a unique way, his role is clear in the studies analyzed, whether he is active as an interviewee or subject who responds to a questionnaire developed with scientific metrics.

Conclusion: The evaluation of graduates is an important strategic tool used by the management of educational institutions, and it can be considered a public policy of significant impact. The evidence confirms the need to incorporate graduates also as protagonists in the institutional self-assessment process.

Keyword: Health Education; Higher Education; Evaluation Studies; Graduate.

1 Universidade Estadual Paulista, São Paulo, São Paulo, Brasil.

Editora-chefe: Rosiane Viana Zuza Diniz.

Editora associada: Maria Viviane Vasconcelos.

Recebido em 23/06/2021; Aceito em 18/12/2021.

Avaliado pelo processo de double blind review. 


\section{INTRODUÇÃO}

É imprescindível destacar os desafios que ocorrem diante das atuais exigências do mundo corporativo. Por conta da grave crise vivida no Brasil, houve aumento do desemprego nos últimos anos ${ }^{1}$, e, com isso, o mercado de trabalho passa a ser mais competitivo e exigente. Tal fato corrobora uma tendência de aumento na procura por cursos de graduação de qualidade, com a finalidade de o cidadão aprimorar as próprias habilidades e obter maior conhecimento corporativo.

A sociedade atual vive uma época em que os trabalhadores deixaram de ser especialistas técnicos, que são bons em realizar tarefas práticas, e passaram a ser especialistas tecnológicos, que possuem habilidades de gestão da informação².

Estudos e publicações governamentais analisados por Vieira et al. ${ }^{3}$, veiculados no período de 2001 a 2011, mostram grande diversidade dos instrumentos de coleta de dados na busca para avaliar o egresso de cursos de Enfermagem quanto à sua formação profissional. A utilização de instrumentos de coleta de dados é interpretada como o desenvolvimento de políticas públicas, visto que a universidade possui um singular papel social ${ }^{4}$.

Além da perspectiva profissional, ressaltam-se os resultados que são oferecidos aos indivíduos que apresentam efetiva mudança de vida por meio da conclusão de um curso, sejam elas mensuráveis ou não, levando-se em conta que o Brasil possui apenas 15,7\% de pessoas com mais de 25 anos que possuem nível superior completo'.

Na Universidade de São Paulo (USP), a avaliação de egressos ocorre a partir do tripé ensino, pesquisa e extensão, sendo desenvolvida de forma centralizada na reitoria e também em suas unidades de ensino ${ }^{4}$. Em 2018, a Universidade Estadual Paulista (Unesp) disponibilizou o portal Alumni Unesp que propicia a conexão de ex-alunos e apresenta notícias, oportunidades de trabalho, solicitação de serviços e contato com a instituição.

De forma semelhante, a Universidade de Yale em New Haven, nos Estados Unidos, possui uma página que atua como papel colaborativo e de responsabilidade social, sendo geradora de relacionamento entre a instituição e os antigos alunos, de modo a proporcionar sinergia benéfica entre os egressos e até o mercado de trabalho ${ }^{5}$. Porém, as redes de conexão de egressos nas universidades mais tradicionais do mundo, comumente chamadas de Alumni, atuam como redes de arrecadação de recursos para as instituições.

Países da União Europeia adotam processos avaliativos com diplomados, envolvendo também familiares e empregadores, e propõem transformações e ajustes curriculares com a colaboração de terceiros especialmente do campo laboral. Em Portugal, diversos estudos são realizados com o foco no papel social da universidade ${ }^{6}$.
Atualmente é possível encontrar trabalhos ${ }^{4,6-8}$ que desenvolvem metodologias de avaliação com a participação do aluno recém-formado. Contudo, reconhecemos a necessidade de verificar que formatos ou modalidades são utilizados no processo de avaliação e se eles têm se mostrado eficientes para a realidade da educação superior brasileira.

A criação de um mecanismo efetivo de coleta de dados dos egressos de um curso é de expressivo significado em qualquer instituição de ensino superior (IES), e sua aplicação não deve ser realizada somente em momentos sazonais, mas também de forma constante para que os benefícios sejam solidificados e priorizem a qualidade do ensino, de modo a fazer parte da cultura da instituição, seja ela pública ou particular.

Este trabalho teve como objetivo conhecer experiências de avaliação de egressos de cursos de graduação da área da saúde no Brasil, a partir da revisão de literatura, identificando processos e o protagonismo do egresso na verificação da qualidade do ensino superior com foco na medicina e enfermagem.

Historicamente, o ensino superior no Brasil assume um papel profissionalizante, com a abertura das primeiras IES. Pontualmente, a primeira Escola de Medicina iniciou seus trabalhos em 1808 com a chegada da Família Real e estava localizada na Bahia. Porém, a educação superior no formato de universidade começou a ser difundida no país na terceira década do século $X X$, com a criação de escolas profissionalizantes com cursos voltados à área médica, ao direito, à engenharia, à artes e aos serviços militares ${ }^{9}$.

A formação acadêmica de qualidade é mais que o preparo profissional para atuação no mercado de trabalho. Ela envolve a formação do ser humano integral como cidadão político e ético ${ }^{10}$.

A corresponsabilização do aluno no processo formativo é decisiva em todas as áreas, mas, na área da saúde, pontos como a responsabilidade na formação inicial do curso, a formação continuada, a autonomia e a responsabilidade social também precisam ser o foco estratégico das instituições de ensino ${ }^{11}$.

A atual sociedade passa por um intenso momento de transformações sociais, e as instituições precisam estar alinhadas e preparadas para lidar com tais mudanças. Por conta disso, os cursos de Medicina e da área da saúde têm incorporado em seus currículos as metodologias ativas com a intenção de estimular a autonomia do aluno e promover a visão de libertação educacional, fazendo com que o discente busque alternativas para consolidar o próprio conhecimento ${ }^{12}$.

A melhoria da qualificação profissional é tida como um diferencial para que o sujeito possa inserir-se no mercado de trabalho. Com base na premissa do capital humano, o investimento em educação é estratégico para a obtenção de 
melhorias sociais e para a potencialização do crescimento social e econômico de comunidades ${ }^{13}$.

A Lei de Diretrizes e Bases (LDB) da Educação Nacional determina que a finalidade da educação superior é "formar diplomados nas diferentes áreas de conhecimento, aptos para inserção em setores profissionais e para participação no desenvolvimento da sociedade brasileira"14 (artigo 43, inciso II). Ao regulamentar a avaliação do sistema educacional brasileiro, a LDB determina no artigo $9^{\circ}$ que cabe ao governo central:

\section{[...] V - coletar, analisar e disseminar informações} sobre a educação;

VI - assegurar processo nacional de avaliação do rendimento escolar no ensino fundamental, médio $e$ superior, em colaboração com os sistemas de ensino, objetivando a definição de prioridades e a melhoria da qualidade do ensino;

[...]

VIII - assegurar processo nacional de avaliação das instituições de educação superior, com a cooperação dos sistemas que tiverem responsabilidade sobre este nível de ensino;

[...]

IX - autorizar, reconhecer, credenciar, supervisionar e avaliar, respectivamente, os cursos das instituições de educação superior e os estabelecimentos do seu sistema de ensino ${ }^{14}$.

À vista desses objetivos, o atual Sistema Nacional de Avaliação da Educação Superior (Sinaes), criado pela Lei $n^{\circ}$ 10.861, de 14 de abril de 2004, tem a seguinte intencionalidade:

[...] articular duas dimensões importantes: a) avaliação educativa propriamente dita, de natureza formativa, mais voltada à atribuição de juízos de valor e mérito em vista de aumentar a qualidade e as capacidades de emancipação e b) regulação, em suas funções de supervisão, fiscalização, decisões concretas de autorização, credenciamento, recredenciamento, descredenciamento, transformação institucional, etc., funções próprias do Estado $^{15}$.

Com um amplo leque de dimensões avaliativas, destaca-se a dimensão em que o aluno é o protagonista. Assim sendo, são objetivos do Sinaes:

[...] melhorar o mérito e o valor das instituições, áreas, cursos e programas, nas dimensões de ensino, pesquisa, extensão, gestão e formação; melhorar a qualidade da educação superior e orientar a expansão da oferta, além de promover a responsabilidade social das IES, respeitando a identidade institucional e a autonomia de cada organização ${ }^{15}$.

Para tanto, congrega um conjunto de estratégias, a saber:

Autoavaliação institucional, conduzida pela Comissão Própria de Avaliação: Cada instituição realiza uma autoavaliação, que será o primeiro instrumento a ser incorporado ao conjunto de mecanismos constitutivos do processo global de regulação e avaliação. A autoavaliação articula um estudo reflexivo segundo o roteiro geral-proposto em nível nacional-, acrescido de indicadores específicos, projeto pedagógico, institucional, cadastro e censo. O relatório da autoavaliação deve conter todas as informações e demais elementos constantes no roteiro comum de base nacional, análises qualitativas e ações de caráter administrativo, político, pedagógico e técnico-científico. Esses aspectos devem guiar o processo de avaliação $e$ identificação dos meios e recursos necessários para a melhoria da IES, bem como uma análise de acertos e equívocos do próprio processo de avaliação.

Exame Nacional do desempenho do estudante-ENADE: O Exame Nacional de Desempenho de Estudantes (Enade) avalia o rendimento dos concluintes dos cursos de graduação, em relação aos conteúdos programáticos, habilidades e competências adquiridas em sua formação. O exame é obrigatório e a situação de regularidade do estudante no Exame deve constar em seu histórico escolar. A primeira aplicação do Enade ocorreu em 2004 e a periodicidade máxima da avaliação é trienal para cada área do conhecimento. O Conceito Enade mantém relação direta com o Ciclo Avaliativo do Enade, sendo os cursos avaliados segundo as áreas de avaliação a ele vinculadas. $O$ Ciclo Avaliativo do Enade foi definido pelo art. 33. da Portaria ${ }^{\circ}$ 40, de 12 de dezembro de 2007, republicada em 2010. Ele compreende a avaliação periódica de cursos de graduação, com referência nos resultados trienais de desempenho dos estudantes.

Avaliação externa: Essa avaliação é feita por membros externos, pertencentes à comunidade acadêmica e científica, reconhecidos pelas suas capacidades em áreas específicas e portadores de ampla compreensão sobre instituições universitárias.

Censo da Educação Superior: O Censo é um instrumento independente que carrega grande potencial informativo, podendo trazer elementos de reflexão para a comunidade acadêmica, para o Estado e para a população em geral. Por isso, é desejável que os instrumentos de coleta de informações censitárias integrem também os processos de avaliação institucional, oferecendo elementos úteis ao entendimento da instituição e do sistema. Os dados do Censo também fazem parte do conjunto de análises e estudos da avaliação institucional interna e externa, contribuindo para a construção de dossiês institucionais e de cursos a serem publicados no Cadastro das Instituições de Educação Superior.

Cadastro de cursos e instituições: De acordo com as orientações do Inep e da Conaes, também são levantadas e disponibilizadas para acesso público às informações do Cadastro das IES e de seus respectivos cursos. Essas informações, que também serão matéria de análise por parte das comissões de avaliação nos processos internos $e$ externos, formarão a base para a orientar de forma 
permanente pais, alunos e a sociedade em geral sobre o desempenho de cursos e instituições ${ }^{15}$.

É importante salientar que a autoavaliação institucional compreende dez dimensões abrangentes. A dimensão "Políticas de atendimento a estudantes e egressos" consiste em dois indicadores básicos: inserção profissional dos egressos e participação dos egressos na vida da IES. À vista disso, esses indicadores são estrategicamente importantes para a gestão da educação superior nacional ${ }^{15}$.

A devolutiva fornecida pelos alunos é muito valiosa para a adequação e revisão do currículo dos cursos, podendo fornecer subsídios para uma nova percepção das experiências educacionais e do ambiente de aprendizagem. $O$ processo avaliativo leva à reflexão e consequentemente à possibilidade de mudança com foco no resultado das atividades educacionais realizadas dentro das instituições ${ }^{12}$.

As avaliações institucionais estão em evolução no Brasil, devido ao interesse das instituições em sistematizar ferramentas que podem ser utilizadas na prática de políticas no ensino superior. A transparência fornecida pelas metodologias de avaliação é muito significativa para a gestão dos cursos e currículos, já que os pontos contraditórios podem ser tratados com dinamismo e transparência ${ }^{16}$.

Institucionalmente existem diversas formas de avaliação educacional, e aquela realizada com base no ponto de vista do aluno é muito importante, independentemente de ele exercer ou não a atividade laboral. Esse tipo de avaliação pode apontar quais melhorias são necessárias para o progresso da educação, considerando que, no dia a dia, esse recém-formado é capaz de confrontar os conhecimentos adquiridos com as atividades efetivamente exercidas. Além disso, pode-se avaliar a adequação dos conteúdos pedagógicos e do processo formativo à atividade laboral ${ }^{16}$.

Apresentar uma ferramenta de avaliação de perfil de egresso perpassa pelo importante processo de validação, que inclui planejar a melhor estratégia de elaboração bem como o melhor método, a escolha de indicadores condizentes com a realidade e o melhor desenho de pesquisa, de acordo com os objetivos da proposta ${ }^{17}$.

\section{MÉTODO}

Para este estudo, foi realizada uma metassíntese, uma modalidade da revisão de literatura, com a finalidade de analisar qualitativamente estudos que tratam da temática da avaliação de egressos do ensino superior. A busca de produções científicas sobre o tema teve como ponto de partida a seguinte questão:

- Como são avaliados os egressos de ensino superior da área médica no Brasil?

Optou-se por empreender uma busca nas principais bases de dados da área da saúde PubMed, Web of Science, LILACS, IBECS e SCiELO, com a utilização dos seguintes descritores: "avaliação de egressos", "avaliação da educação médica" e "avaliação de graduados".

A escolha das bases de dados se deu devido à possibilidade de encontrar trabalhos da saúde, em específico das áreas médica e enfermagem, com experiências significativas.

Obteve-se um total de 245 trabalhos, e, após a utilização de critérios de inclusão, selecionaram-se 13 trabalhos que foram submetidos à análise qualitativa. Os trabalhos encontrados foram selecionados por meio da leitura do título e resumo, e, na escolha dos textos, consideraram-se os critérios apresentados na Figura 1.

Foram considerados os trabalhos que apresentavam no mínimo três seleções "sim".

A pesquisa nas bases de dados ocorreu entre os meses de abril e maio de 2019, e não foram adicionados filtros temporais nas pesquisas; optou-se por analisar os trabalhos nacionais.

Salvaram-se todos os artigos no Excel. Os aspectos principais deles foram registrados também em planilha do Excel, analisados individualmente e, depois, comparados com foco no protagonismo do egresso e na forma de avaliação (questionário, entrevista ou outra forma de participação). Observaram-se os seguintes aspectos nos trabalhos encontrados: protagonismo do egresso nos processos de avaliação, indicadores relacionados à qualidade da educação e avaliação de egressos como política pública.

Figura 1. Ficha de avaliação de artigos.

\begin{tabular}{clll}
\hline \multicolumn{5}{c}{$\begin{array}{c}\text { Ficha de avaliação de artigos } \\
\text { Avaliação de Egressos da área da saúde }\end{array}$} \\
\hline 1 & Trabalho com desenvolvimento de questionários de avaliação de egressos & () Sim & () Não \\
\hline 2 & Trabalho com avaliação de egressos & () Sim & () Não \\
3 & Trabalho com participação de egressos & () Sim & () Não \\
\hline 4 & Trabalho com indicadores de qualidade na educação superior & () Sim & () Não \\
\hline 5 & Desenvolvimento de metodologia de avaliação da educação superior & ()Sim & () Não \\
\hline
\end{tabular}

Fonte: Elaborada pelas autoras. 


\section{RESULTADOS}

A partir da leitura e análise qualitativa dos trabalhos, elaborou-se um quadro com a síntese dos principais aspectos buscados na literatura selecionada, com os seguintes destaques: "autor/ano publicação", "título" e "considerações".

A Figura 2 apresenta os temas considerados na análise dos trabalhos encontrados.

\section{DISCUSSÃO}

Considerando que o produto final da educação é a formação de conhecimento do sujeito, buscou-se neste trabalho verificar como são feitas as avaliações de egressos da área da saúde.

A maioria dos trabalhos apresentou estudos de desenvolvimento e validação de instrumentos em forma de

Quadro 1.

\begin{tabular}{|c|c|c|c|}
\hline & AUTOR & TíTULO & CONSIDERAÇÕES \\
\hline 1 & Vieira et al. $(2016)^{3}$ & $\begin{array}{l}\text { "A construção e validação de um } \\
\text { instrumento para avaliação de } \\
\text { egressos" }\end{array}$ & $\begin{array}{l}\text { Instrumento validado de acordo com as Diretrizes } \\
\text { Curriculares Nacionais (DCN) com a participação dos } \\
\text { egressos respondendo ao questionário. }\end{array}$ \\
\hline 2 & Francisco et al. (2016) & $\begin{array}{l}\text { "Avaliação da formação de enfermeiros: } \\
\text { o reflexo dos métodos de ensino- } \\
\text { aprendizagem e pressupostos } \\
\text { curriculares na prática profissional" }\end{array}$ & $\begin{array}{l}\text { Questionário sobre aspectos socioeconômicos, atuação } \\
\text { e avaliação do curso, e uma narrativa com aspectos de } \\
\text { sua formação e vivência profissional. }\end{array}$ \\
\hline 3 & Lima et al. $(2018)^{19}$ & $\begin{array}{l}\text { "Acompanhamento de egressos: } \\
\text { subsídios para a avaliação de } \\
\text { instituições de ensino superior (IES)" }\end{array}$ & $\begin{array}{l}\text { Alunos responderam a um questionário: parte } \\
\text { presencialmente e parte via contato telefônico. }\end{array}$ \\
\hline 4 & Andriola $(2014)^{20}$ & $\begin{array}{l}\text { "Estudo de egressos de cursos } \\
\text { de graduação: subsídios para a } \\
\text { autoavaliação e o planejamento } \\
\text { institucionais" }\end{array}$ & $\begin{array}{l}\text { Egressos responderam a um questionário on-line que } \\
\text { verificava informações laborais, percepção do mercado } \\
\text { de trabalho e satisfação com o curso. }\end{array}$ \\
\hline 5 & Senger et al. $(2018)^{21}$ & $\begin{array}{l}\text { "Trajetória profissional de egressos do } \\
\text { curso de Medicina da Universidade de } \\
\text { Campinas (Unicamp), São Paulo, Brasil: } \\
\text { o olhar do ex-aluno na avaliação do } \\
\text { programa" }\end{array}$ & $\begin{array}{l}\text { Questionário semiestruturado aplicado após reforma } \\
\text { curricular e respondido pelos egressos digitalmente. }\end{array}$ \\
\hline 6 & Meira et al. $(2008)^{22}$ & $\begin{array}{l}\text { "Avaliação da formação de enfermeiros } \\
\text { segundo a percepção de egressos" }\end{array}$ & $\begin{array}{l}\text { Revisão que aborda a avaliação de cursos de graduação } \\
\text { sob a perspectiva do egresso. }\end{array}$ \\
\hline 7 & Tonhom $(2008)^{23}$ & $\begin{array}{l}\text { "Os egressos como atores do processo } \\
\text { de avaliação curricular do curso de } \\
\text { Enfermagem da Famema" }\end{array}$ & $\begin{array}{l}\text { Os egressos participaram da avaliação após três anos } \\
\text { de graduação. Trabalho realizado com entrevistas } \\
\text { semiestruturadas. }\end{array}$ \\
\hline 8 & Hafner et al. $(2010)^{24}$ & $\begin{array}{l}\text { "A formação médica e a clínica ampliada: } \\
\text { resultados de uma experiência brasileira" }\end{array}$ & $\begin{array}{l}\text { O egresso participou da avaliação respondendo a } \\
\text { entrevistas semiestruturadas com foco na formação } \\
\text { clínica ampliada. }\end{array}$ \\
\hline 9 & Torres et al. $(2012)^{25}$ & $\begin{array}{l}\text { "Inserção, renda e satisfação profissional } \\
\text { de médicos formados pela Unesp" }\end{array}$ & $\begin{array}{l}\text { Os egressos responderam a um questionário enviado } \\
\text { pelos Correios. O estudo avaliou os egressos de um } \\
\text { intervalo de mais de } 30 \text { anos. }\end{array}$ \\
\hline 10 & Torres et al. $(2011)^{26}$ & $\begin{array}{l}\text { "Qualidade de vida e saúde física e } \\
\text { mental de médicos: uma autoavaliação } \\
\text { por egressos da Faculdade de Medicina } \\
\text { de Botucatu - Unesp" }\end{array}$ & $\begin{array}{l}\text { Os egressos apresentaram feedback sobre a qualidade } \\
\text { de vida por meio de respostas a um questionário } \\
\text { encaminhado pelos Correios. A satisfação pessoal teve } \\
\text { um peso importante. }\end{array}$ \\
\hline 11 & Meira et al. $(2018)^{27}$ & $\begin{array}{l}\text { "Avaliação de curso de graduação } \\
\text { segundo egressos" }\end{array}$ & $\begin{array}{l}\text { Revisão sobre a avaliação de cursos superiores no Brasil, } \\
\text { tendo a perspectiva do egresso como indicador. }\end{array}$ \\
\hline 12 & Falavigna et al. $(2013)^{28}$ & $\begin{array}{l}\text { "Sistema de saúde e educação médica no } \\
\text { Brasil: história, princípios e organização" }\end{array}$ & $\begin{array}{l}\text { Revisão sobre a educação médica no Brasil com a } \\
\text { participação do egresso no momento da devolutiva. } \\
\text { O estudo não especifica outros métodos de avaliação } \\
\text { com a participação do aluno. }\end{array}$ \\
\hline 13 & Poles et al. $(2018)^{29}$ & $\begin{array}{l}\text { "Percepção dos internos e recém- } \\
\text { egressos do curso de Medicina da PUC- } \\
\text { SP sobre sua formação para atuar na } \\
\text { atenção primária à saúde" }\end{array}$ & $\begin{array}{l}\text { Os alunos responderam a um questionário com } \\
\text { questões abertas e fechadas sobre sua satisfação e } \\
\text { percepção sobre o curso. }\end{array}$ \\
\hline
\end{tabular}

Fonte: Elaborado pelas autoras. 
Figura 2. Temas para a avaliação.

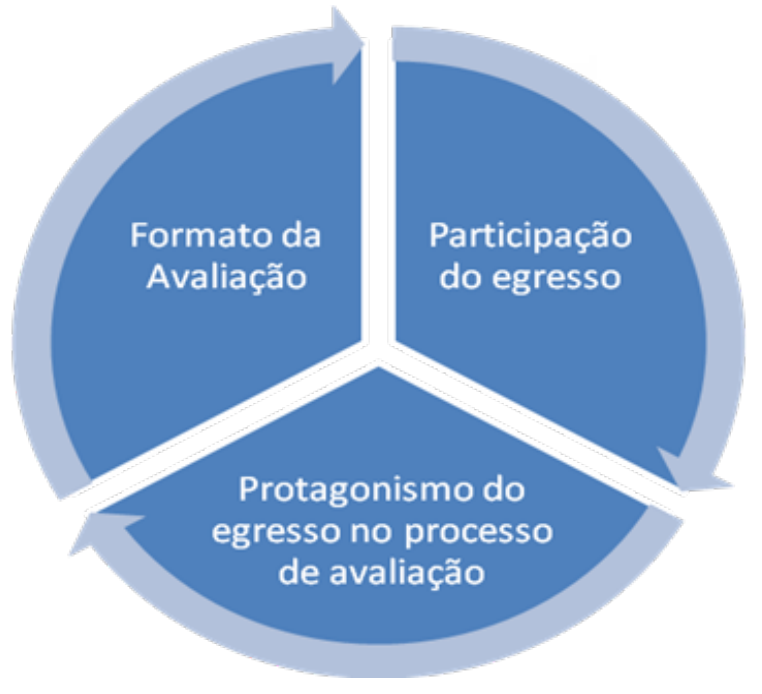

Fonte: Elaborada pelas autoras.

questionário, aplicados em turmas de alunos concluintes dos cursos de Medicina e Enfermagem. A literatura aponta diversificadas formas de validação de ferramentas avaliativas, com destaque para trabalhos que utilizam o método DELPHI, que consiste na verificação da concordância de opiniões de especialistas da área em questão.

De acordo com Francisco et al. ${ }^{18}$ e Andriola ${ }^{20}$, a inserção do recém-formado no mercado de trabalho - isto é, o aluno conclui o curso e consegue sua colocação - é considerado um indicador positivo para a universidade. Aqui se aponta o importante papel social da IES, pois, quando é verificada a inserção solidificada de um sujeito com qualificações no mercado de trabalho, considerase que a instituição cumpriu sua "missão".

Destaca-se também o fato de esta revisão analisar a avaliação da área saúde com reflexos importantes na área do bem-estar da população, considerando que um bom médico e um bom enfermeiro que estão bem colocados no mundo do trabalho representam a geração de renda para famílias e também a disponibilização de serviços de qualidade para a sociedade.

Como as comunidades são beneficiadas direta ou indiretamente pelo desenvolvimento do conhecimento fomentado nas universidades, a avaliação de um curso da instituição por meio da opinião das "sementes" plantadas, que são os egressos, é capaz de mensurar parte dessa formação profissional; afinal, o egresso, além de ocupar o papel social de trabalhador e gerador de renda, também pode atuar como multiplicador do conhecimento e boas práticas, além de desenvolvedor de tecnologias, que podem retornar para a população, como fármacos, protocolos e procedimentos clínicos eficientes e muitas vezes até econômicos.

Outro ponto analisado nos trabalhos de Lima et al. ${ }^{19}$ e Poles et al. ${ }^{29}$ foi a satisfação do egresso acerca da formação recebida. O nível de satisfação do egresso com o seu processo de formação é um importante indicador da instituição de ensino. Foi possível encontrar de forma constante a abordagem das Diretrizes Curriculares Nacionais (DCN). Nos artigos de Vieira et al. $^{3}$ e Senger et al. ${ }^{21}$, existe a comparação de indicadores antes e depois da adequação às DCN.

Encontraram-se estudos de caso em que se utilizaram entrevistas com os egressos, a fim de subsidiar a reformulação de currículos com foco no processo formativo, fugindo um pouco do tema de inserção no mercado de trabalho.

Uma temática abordada no trabalho de Hafner et al. ${ }^{24}$ foi a avaliação do egresso com enfoque na formação do médico generalista, humanista ou crítico reflexivo, que trata de avaliar a formação do profissional fora da ótima empregatícia ou da alteração de conteúdos institucionais.

Um estudo retrospectivo realizado por Torres et al. ${ }^{27}$ apresenta a utilização de envio de questionário autoaplicável, via Correios, com um intervalo de 37 anos, com uma taxa de resposta de $45 \%$. Estudos com a utilização dessa metodologia podem traçar o perfil do egresso com possibilidade de comparar dados com o passar dos anos. O mesmo grupo realizou o trabalho de verificação da qualidade de vida de egressos do curso de Medicina, com a utilização da mesma metodologia, e apontou que a saúde física e mental dos egressos está associada à qualidade de vida deles. Portanto, neste trabalho foi possível encontrar o egresso inclusive como protagonista da avaliação da qualidade de vida.

\section{CONSIDERAÇÕES FINAIS}

A trajetória percorrida para a elaboração deste trabalho permite concluir que, entre os formatos de avaliação que consideram o protagonismo do egresso, encontramse, preferencialmente, questionários impressos e on-line, e entrevistas estruturadas e semiestruturadas. É possível apontar ainda que o egresso participa do processo de avaliação de forma singular, já que sua atuação fica fulgente nos estudos analisados, seja ele atuante como entrevistado ou sujeito que responde ao questionário desenvolvido com métricas científicas.

Assim, a avaliação de egressos é uma importante ferramenta estratégica utilizada pela gestão de instituições de ensino, podendo ser considerada uma política pública de significativo impacto quando se trata da avaliação de alunos de universidades públicas. As evidências ratificam a necessidade de incorporação de egressos também como protagonistas nos processos de autoavaliação institucional.

\section{CONTRIBUIÇÃO DAS AUTORAS}

Tamiris Mariani Pereira Desiderio é autora principal, desenvolvedora da pesquisa e da redação do artigo 
apresentado. Ana Silvia Sartori Barraviera Seabra Ferreira participou da redação e revisão do artigo.

\section{CONFLITO DE INTERESSES}

Declaramos não haver conflito de interesses.

\section{FINANCIAMENTO}

Declaramos não haver financiamento.

\section{REFERÊNCIAS}

1. Instituto Brasileiro de Geografia e Estatística. Indicadores IBGE: pesquisa mensal de emprego 2016. Brasília: IBGE; 2016 [acesso em 11 jun 2019]. Disponível em: http://ftp.ibge.gov.br/Trabalho_e_Rendimento/Pesquisa_ Mensal_de_Emprego/fasciculo_indicadores_ibge/2016/.

2. Strauhs FR, Pietrovski EF, Santos GD, Carvalho HG, Pimenta RB, Penteado RSG. Gestão do conhecimento nas organizações. Curitiba: Aymará Educação; 2012.

3. Vieira MA, Ohara CVS, Domenico EBL. The construction and validation of an instrument for the assessment of graduates of undergraduate nursing courses. Rev Lat Am Enfermagem. 2016;24:e2710. doi: 10.1590/15188345.0834.2710.

4. Miranda CS, Pazello ET, Lima CB. Egressos como instrumento de avaliação institucional: uma análise da formação e empregabilidade dos egressos da FEA-RP/USP. Rev Gestão Univ Am Lat. 2015;8(1):298-321. doi: 10.5007/1983-4535.2015v8n1p298.

5. Ferraz FAVGD, Fernandes IB, Schon M. Interacção universidade-empresa: o portal Alumni como instrumento socialmente responsável e de design colaborativo. Anais do XI Seminário Luso-Espanhol de Gestão Empresarial; 12-13 Nov 2009; Faro, Portugal. Faro: Cibecem; 2009. p. 1-15.

6. Coelho MSC, Oliveira NCM. Os egressos no processo de avaliação. Rev e-Curric. 2012;9(2) [acesso em 7 jun 2021]. Disponível em: https://revistas. pucsp.br/index.php/curriculum/article/view/10855.

7. Ferreira AS, Barraviera B, Barraviera SR, Abbade LP, Caramori CA, Ferreira Júnior RS. A success in toxinology translational research in Brazil: bridging the gap. Toxicon. 2013;69:50-4. doi: 10.1016/j.toxicon.2013.01.003.

8. Machado CDB, Wuo A, Heinzle M. Educação médica no Brasil: uma análise histórica sobre a formação acadêmica e pedagógica. Rev Bras Educ Med. 2018;42(4):66-73. doi: 10.1590/1981-52712015v42n4rb20180065.

9. Martins ACP. Ensino superior no Brasil: da descoberta aos dias atuais. Acta Cir Bras. 2002;17 (supl 3):4-6. doi: 10.1590/S0102-86502002000900001.

10. Gonçalves $\mathrm{ML}$, Pereira E. Contribuições da educação geral na formação de médicos e pedagogos egressos de uma universidade pública. Avaliação. 2015;20(2):513-30. doi: 10.590/S1414-40772015000200012.

11. Purim KSM, Tizzot ELA. Protagonismo dos estudantes de Medicina no uso do Facebook na graduação. Rev Bras Educ Med. 2019;43(1):187-96. doi: 10.1590/1981-52712015v43n1rb20180139.

12. Lima Filho PRS, Marques RVDA. Perspectivas sobre o aprendizado na óptica de estudantes de medicina: análise do impacto de transição curricular. Rev Bras Educ Med. 2019;43(2):87-94. doi: 10.1590/1981-52712015v43n2 rb20170124.

13. Lemos AHC, Dubeux VJC, Pinto MCS. Educação, empregabilidade e mobilidade social: convergências e divergências. Cad EBAPE.BR. 2009;7(2):368-84. doi: 10.1590/S1679-39512009000200012.
14. Brasil. Lei no 9.394, de 20 de dezembro de 1996. Estabelece as diretrizes e bases da educação nacional. Brasília; 1996 [acesso em 7 jun 2021] Disponível em: http://www.planalto.gov.br/ccivil_03/leis/19394.htm.

15. Brasil. Sinaes: O que é o Sinaes. Brasília: Inep; 2015 [acesso em 7 jun 2021]. Disponível em: http://inep.gov.br/sinaes.

16. Camara AMCS, Santos LLCP. Um estudo com egressos do curso de Fisioterapia da Universidade Federal de Minas Gerais (UFMG): 1982 2005. Rev Bras Educ Med. 2012(36 supl 1):5-17. doi:10.1590/S0100 55022012000200002 .

17. Alexandre NMC, Coluci MZ. O. Validade de conteúdo nos processos de construção e adaptação de instrumentos de medidas. Ciênc Saúde Colet. 2011;16(7):3061-8. doi: 10.1590/S1413-81232011000800006.

18. Francisco AM, Costa MCG, Hamamoto CG, Hafner MLMB. Avaliação da formação de enfermeiros: o reflexo dos métodos de ensino-aprendizagem e pressupostos curriculares na prática profissional. Avaliação. 2016;21(2):479-502. doi: 10.1590/S1414- 40772016000200009.

19. Lima LA, Andriola WB. Acompanhamento de egressos: subsídios para a avaliação de instituições de ensino superior (IES). Avaliação. 2018;23(1):104-25. doi: 10.1590/s1414-40772018000100007.

20. Andriola WB. Estudo de egressos de cursos de graduação: subsídios para a autoavaliação e o planejamento institucionais. Educ Rev. 2014;(54):20320. doi: 10.1590/0104-4060.36720.

21. Senger MH, Campos MCG, Servidoni MFCP, Passeri SMRR, Velho PENF Toro IFC, et al. Trajetória profissional de egressos do curso de Medicina da Universidade de Campinas (Unicamp), São Paulo, Brasil: o olhar do ex-aluno na avaliação do programa. Interface (Botucatu). 2018;22(supl 1):1443-55. doi: 10.1590/1807-57622017.0190.

22. Meira MDD, Kurcgant P. Avaliação da formação de enfermeiros segundo a percepção de egressos. Acta Paul Enferm. 2008;21(4):556-61. doi: 10.1590/ S0103-21002008000400004.

23. Tonhom SFR. Os egressos como atores do processo de avaliação curricular do curso de Enfermagem da Famema. Interface (Botucatu) 2008;12(27):931. doi: 10.1590/S1414-32832008000400025.

24. Hafner MLMB, Moraes MAA, Marvulo MML, Braccialli LAD, Carvalho MHR, Gomes R. A formação médica e a clínica ampliada: resultados de uma experiência brasileira. Ciênc Saúde Colet. 2010;15(supl 1):1715-24. doi: 10.1590/S1413-81232010000700083.

25. Torres AR, Ruiz T, Müller SS, Lima MCP. Inserção, renda e satisfação profissional de médicos formados pela Unesp. Rev Bras Educ Med. 2012;36(1):32-40. doi: 10.1590/S0100-55022012000100005.

26. Torres AR, Ruiz T, Müller SS, Lima MCP. Qualidade de vida e saúde física e mental de médicos: uma autoavaliação por egressos da Faculdade de Medicina de Botucatu - Unesp. Rev Bras Epidemiol. 2011;14(2):264-75. doi: 10.1590/S1415-790X2011000200008.

27. Meira MDD, Kurcgant P. Evaluación del curso de graduación según los egresados. Rev Esc Enferm USP. 2009;43(2):481-5. doi: 10.1590/S008062342009000200031.

28. Falavigna A, Canabarro CT, Medeiros GS. Health system and medical education in Brazil: history, principles, and organization. World Neurosurg 2013;80(6):723-7. doi: 10.1016/j.wneu.2013.01.079.

29. Poles TPG, Oliveira RA, Anjos RMP, Almeida FA. Percepção dos internos e recém-egressos do curso de Medicina da PUC-SP sobre sua formação para atuar na atenção primária à saúde. Rev Bras Educ Med. 2018;42(3):121-8. doi: 10.1590/1981-52712015v42n3rb20170072. 